\title{
Emoções e pesquisa narrativa: transformando experiências de aprendizagem $^{1}$
}

Rodrigo Aragão

Universidade Estadual de Santa Cruz

\begin{abstract}
RESUMO: Este artigo explora a influência de uma pesquisa narrativa nas experiências de aprendizagem de estudantes de Letras/Inglês. Ao refletir sobre suas histórias de aprendizagem, eles deram voz e sentido às suas experiências, sentindo-se valorizados. Suas histórias de aprendizagem expōem a relevância das emoçôes no desenvolvimento de habilidades orais, na reflexão e na responsabilidade por sua trajetória profissional. Três participantes transformaram suas experiências de aprendizagem de inglês ao refletir sobre as emoções que limitam seu desempenho oral e ao projetar imagens que representassem o desejo de se tornarem falantes fluentes. Porém, transformar os desejos em ações pode envolver investimentos que extrapolam a tomada de consciência na reflexão pela pesquisa.
\end{abstract}

PALAVRAS-CHAVE: pesquisa narrativa; emoçōes; experiências de aprendizagem; inglês

\section{Introdução}

Seja como tema de pesquisa ou não, nossas emoções se fazem presentes em nossas vidas nos mais diversos âmbitos e de diferentes maneiras, modulando o fluir de nossas ações. Como não pode deixar de ser, as emoções estão presentes também na aprendizagem de uma língua estrangeira. Hoje, no cenário internacional da Lingüística Aplicada, é crescente o interesse pelo papel das emoções no ensino e na aprendizagem de línguas, e não é demais dizer que este vem se tornando um dos temas vibrantes e complexos da área (Cf. ARNOLD, 1999; PAVLENKO, 2005; SCHUMANN, 1997). Defino aqui as emoções como disposições corporais dinâmicas que modulam ações e relações

\footnotetext{
${ }^{1}$ Este artigo é um recorte da tese de doutorado São as Histórias que Nos Dizem Mais: emoção, reflexãa e ação na sala de aula, orientado pela Dra. Cristina Magro. Agradeço a Cristina Magro, Élida Ferreira e aos pareceristas desta revista pelas sugestōes a uma versão preliminar deste artigo.
} 
possíveis, num dado momento de um fluir histórico (cf. MATURANA, 1998; BOOTH; PENNEBAKER, 2000; ARAGÃO, 2005). São com as emoçóes que agimos de maneira expansiva na felicidade e curiosidade, no movimento contrário a alguém ou algo com raiva, com retraimento e restrição na vergonha. Desta maneira, as emoções não se expressam, mas fluem com elas. Ao mudar de emoção, mudamos de ação, um fluir denominado de emocionar (MATURANA; BLOCK, 1996, p. 117). Entretanto, na linguagem, ao observar a própria conduta, ou a de uma outra pessoa, pode-se refletir, distinguindo o observado, e assim falar da emoção como um sentimento. Este aspecto difuso das emoções é recorrente em situações na sala de aula: o medo de se expressar pode levar o aluno a não falar em inglês e a restringir seu processo de reflexão, dificultando a superação da dificuldade.

Portanto, é a reflexão que possibilita vermos a dinâmica emocional, ao descrever o que se vive no fluir contínuo da experiência. Se olharmos o nosso emocional, de maneira reflexiva, podemos atuar coerentemente com ele ou podemos mudar de domínio de ação, se assim o desejamos. Além disso, ao dar-se conta da conseqüência de nossas emoçóes em nossa conduta, abrimos espaço para uma atitude responsável. $\mathrm{Na}$ sala de aula de língua estrangeira, as emoções cumprem papel relevante na aprendizagem e se ligam a questões caras ao cotidiano do professor, quais sejam: despertar e manter o interesse pela aprendizagem da língua; envolver estudantes nas dinâmicas conversacionais; fomentar a responsabilidade por sua aprendizagem; lidar com alunos resistentes ou temerosos de se expressar na sala de aula.

$\mathrm{Na}$ Lingüística Aplicada, pesquisas qualitativas com narrativas de aprendizagem têm se mostrado produtivas na compreensão das experiências de estudantes de uma língua em diversos contextos e referenciais teóricos (Cf. ARAGÃO, 2005; BENSON; NUNAN, 2004; SWAIN; MICCOLI, 1994; BARCELOS, 2006; PAIVA, 2007a). Nessas pesquisas, as narrativas de aprendizagem fomentam a reflexão sobre as dinâmicas da experiência humana, "concebida como um processo complexo de relações e inter-relações" (MICCOLI, 2007, p. 240), mostrando como o ensino/aprendizagem de uma língua envolve um sistema imbricado de emoçôes, crenças, ideologias, identidades, relações e desafios. A reflexão consciente desencadeada nas narrativas de aprendizagem tem o poder de fomentar o desenvolvimento de estudantes (ARAGÃO, 2007; SWAIN; MICCOLI, 1994; MICCOLI, 1997, 2007). Swain e Miccoli (1994), ao investigarem as experiências de Hiroko, uma aluna japonesa de inglês no Canadá, indicaram como ela passou a perceber 
e compreender os aspectos emocionais que dificultavam sua participação em tarefas colaborativas na sala de aula. Sua trajetória na disciplina passou por três fases: ansiedade, depressão e felicidade. Neste último estágio, a aluna sentiu que era valorizada pelos colegas e que contribuía para o desenvolvimento das atividades. Nesta fase, Hiroko foi capaz de agir de maneira expansiva no acolhimento e na felicidade, transformando sua experiência em sala de aula. Miccoli (1997), ao investigar as experiências de estudantes universitários brasileiros, indicou que experiências sociais e emocionais acompanham as cognitivas e que a variabilidade de desempenho dos estudantes pode ser atribuída a diferentes experiências prévias, crenças e relações emocionais em sala de aula. Uma experiência recorrente foi a não participação de alunos em tarefas orais por medo de serem criticados pelos colegas.

De maneira similar aos estudos de Miccoli (1997) e Swain e Miccoli (1994), Aragão (2007) indicou como um estudante de Letras-Inglês atua em sua sala de aula influenciado por diversos elementos oriundos de sua história prévia à universidade, mas, sobretudo e de maneira contundente, por suas emoções. Ao refletir sobre suas histórias de aprendizagem com o pesquisador, sete estudantes deram sentido à sua experiência e sentiram-se valorizados. $\mathrm{Na}$ reflexão, eles se transformaram em sujeitos agentes de sua prática, observando seus desafios e como poderiam superá-los, mesmo aqueles que, naquele semestre, não conseguiram pôr em prática o que a sua reflexão fez emergir, em termos da conscientização do papel de suas emoções em seu processo de aprendizagem. Destaca-se em Aragão (2007) a utilização de imagens para representar as emoções quanto ao desafio de se falar inglês e o fluir das experiências no semestre letivo, atividade que potencializou a reflexão.

Diante dessas consideraçóes, este artigo tem como objetivo: 1) reforçar a importância de se criar oportunidades em sala de aula para a reflexão sobre o processo de aprendizagem; 2) indicar a relevância das emoções em práticas reflexivas; 3) refletir sobre as emoções de três estudantes no desenvolvimento de habilidades orais em inglês; 4) tecer consideraçôes sobre a influência da pesquisa na transformação de experiências de aprendizagem.

No que segue, aponto a Pesquisa Narrativa como uma epistemologia apropriada para a compreensão de experiências de aprendizagem de língua estrangeira como proposto aqui. Em seguida, exponho o contexto, os participantes e os procedimentos desta pesquisa para, então, discutir como as histórias de aprendizagem dos participantes expõem a relevância das emoções no desenvolvimento de habilidades orais, na reflexão e na responsabilização por sua trajetória profissional. 


\section{Pesquisa narrativa}

Atualmente, segundo Barcelos (2006, p. 146), "o interesse por narrativas e histórias como instrumento e como abordagem de pesquisa na análise de aspectos do processo de ensino e aprendizagem de línguas vem crescendo no Brasil e no mundo". Na Lingüística Aplicada, o trabalho de Clandinin e Connely (2000) tem sido referência, em especial, no campo de formação de professores (JOHNSON; GOLOMBECK, 2002; TELLES, 2002, 2004) e a área de formação reflexiva de professores se encontra com produção crescente (Cf. LEFFA, 2001; CELANI, 2003; ABRAHĀO, 2004). Comumente, utiliza-se a Pesquisa Narrativa que auxilia no desenvolvimento da prática e a responsabilidade neste processo contínuo, evidenciando o valor da reflexão como elemento transformador de experiências de ensino e de aprendizagem. Narrativas têm sido utilizadas também para pesquisar distintos elementos presentes nos processos de ensino e de aprendizagem de uma segunda língua na perspectiva dos estudantes (OXFORD; GREEN, 1996; BENSON; NUNAN, 2004; PAIVA, 2005, 2007a; BARCELOS, 2006). Essas pesquisas têm demonstrado como os processos de aprendizagem de língua exibem extensa variação individual, devido a um complexo sistema de elementos de natureza histórica, sociocultural, cognitiva e emocional. De fundamental importância, estes estudos sugerem que a utilização de narrativas auxilia o desenvolvimento consciente e efetivo de alunos e professores de línguas.

$\mathrm{Na}$ Pesquisa Narrativa, os participantes e o pesquisador são compreendidos como co-construtores e como co-agentes envolvidos na construção da pesquisa. Essa modalidade de pesquisa propõe uma parceria com o participante na construção das histórias e na compreensão da experiência educacional (TELLES, 2002). Em um processo contínuo de negociação na convivência com os participantes, o pesquisador mergulha num turbilhão de histórias e de ações, vivendo, ao mesmo tempo, sua própria história e as histórias de outros, procurando conexóes, padróes e sentidos, entre histórias relatadas, experiências vividas e observadas. Nesse processo, o pesquisador adentra dimensões temporais, contextuais e pessoais, ao coletar diversos documentos de pesquisa, como autobiografias escritas, diários, poemas, artefatos pessoais, narrativas orais, dentre outros (CLANDININ; CONNELY, 2000).

Ao entrecruzar as observações realizadas, o pesquisador busca produzir textos de pesquisa, ou seja, relatos escritos das histórias e ações dos participantes, imputando-lhes um enredo histórico e tecendo interpretações, 
ao conectar diversos elementos que compóem a experiência do participante (TELLES, 2002). De acordo com Paiva (2005, p. 1) "as narrativas conferem significados a contextos de aprendizagem na perspectiva dos aprendizes, pois são eles que explicam como aprendem ou aprenderam uma língua”. Clandinin e Connelly (2000), citando Dewey (1938), argumentam que o conceito de continuidade de Dewey aponta para as relaçôes contínuas da experiência temporal humana, tendo em mente o passado que levou a este presente e que pode nos projetar para um determinado futuro. Neste aspecto, é importante termos em mente que o que três participantes desta pesquisa, Arwen, Sollylove e Júlia, "vivenciaram no passado afeta como se percebem como aprendizes e como experiências prévias tingem suas primeiras experiências na aprendizagem de línguas na universidade" (BARCELOS, 2006, p. 162).

Ainda, como sugere Telles (2004, p. 80), ao narrar suas experiências, os alunos podem reavaliar suas histórias e partir para outras com as quais desejam viver, de forma que reflexão e emoção caminham juntas. Vale ressaltar que, nesse âmbito, Norton $(2000$, p. 5) usa o termo identidade para se referir à maneira pela qual uma pessoa compreende sua relação experiencial com o mundo, como esta relação é construída no tempo e no espaço e como esta pessoa cria possibilidades para o futuro. Essa definição do termo se associa à Pesquisa Narrativa de Clandinin e Connely (2000), que tende a conceituar o termo como "as histórias pelas quais vivemos", que tem sentido no conceito de continuidade de experiências de Dewey (TELLES, 2004).

\section{Contexto, participantes e procedimentos da pesquisa}

Esta pesquisa foi conduzida na Faculdade de Letras (FALE) da Universidade Federal de Minas Gerais (UFMG). No campo profissional, a FALE é a instituição à qual estive vinculado como aluno, estagiário/professor e pesquisador. Desde a licenciatura em inglês, interessei-me em pesquisar esse espaço de formação e contribuir para uma maior compreensão da experiência vivida.

Para a pesquisa foi escolhida a disciplina Habilidades Integradas I: Inglês, porque esta é o primeiro contato que o aluno tem com o inglês na graduação. Assim, poderia oferecer a observação comparativa entre as experiências prévias dos alunos e sua formação inicial. As disciplinas Habilidades Integradas I, II e III são pré-requisito para cursar as demais disciplinas, para os que optam pela habilitação em inglês, a saber: Fonologia, Expressão Oral, Produção de Textos, 
Sintaxe e literaturas de expressão inglesa. ${ }^{2} \mathrm{Na}$ disciplina Habilidades Integradas I, trabalha-se a comunicação nas quatro habilidades, em nível intermediário, através de um livro texto. ${ }^{3}$ A disciplina visa ainda: a) aprimorar a pronúncia e introduzir o alfabeto fonético; b) praticar escrita acadêmica; c) desenvolver conhecimentos metalingüísticos, ou seja, tomar consciência de terminologia formal. ${ }^{4}$ A professora encarregada da disciplina via o ensino de metalinguagem ${ }^{5}$ como o foco central de suas atividades naquele semestre. A professora definia seu estilo de ensino como centrado no professor, pois enfatizava atividades nas quais detinha maior controle dos turnos e das ações pedagógicas.

Dos vinte e quatro alunos matriculados na disciplina, sete participaram da pesquisa, adotando um nome fictício de sua escolha: Arwen, Sollylove, Júlia, Carlos, Nathy, Faily e Cheguevara. Neste artigo, enfatizo as experiências de Arwen, Sollylove e Júlia. ${ }^{6}$

Arwen mora em Belo Horizonte com os pais e um irmão mais velho. Gosta de "mexer" na internet, ouvir música e ver filmes em inglês. Tinha 21 anos e estava no primeiro semestre do curso de Letras. Entre os participantes, foi com quem mais conversei sobre timidez em sala de aula. Não tinha a expectativa de se tornar professora por sua timidez.

Sollylove veio do interior de Minas Gerais, para cursar Letras na UFMG naquele semestre. "Tudo pelo inglês", dizia em sua autobiografia escrita aos 22 anos. Tinha enorme prazer de cantar em inglês. Queria se tornar professora. Dada sua intensa participação na pesquisa, além do modo descontraído como se comportava nos corredores da FALE, sua inibição em sala de aula era algo de se estranhar.

\footnotetext{
${ }^{2}$ Para maiores informações quanto à proposta curricular, ementa de disciplinas e projeto pedagógico da Faculdade de Letras da UFMG, favor acessar www.letras.ufmg.br.

${ }^{3} \mathrm{Na}$ época da pesquisa, o livro adotado foi HUTCHINSON, T. LifeLines Intermediate: Oxford: Oxford University Press, 1997. Os alunos que não estão no nível intermediário são orientados a participar de projetos institucionais que os auxiliam a desenvolver sua proficiência e estratégias de aprendizagem.

${ }^{4}$ Agradeço a Profa. Dra. Herzila Bastos por revisar as informaçōes contidas neste parágrafo. ${ }^{5}$ Segundo Dutra (2004, p.20) a metalinguagem é "o uso da língua para descrever ou analisar um fenômeno lingüístico com terminologia explícita ou sem ela ou também de maneira implícita".

${ }^{6}$ Ressalto que a história individual de Júlia resultou em outro trabalho (ARAGÃO, 2005), e que sua inclusão neste artigo se dá pelas semelhanças experienciais vividas pelas três.
} 
Júlia foi criada em Belo Horizonte: "Venho de família simples e que sempre batalhou para chegar onde está hoje". Assim descrevia a vida da família e sua aprendizagem de inglês: como uma batalha. Tinha 23 anos, quando nos conhecemos, e estava no quinto período do curso. Era repetente na disciplina e, "pisando em ovos", era como se via em sala de aula. Tinha se tornado professora de inglês para crianças naquele semestre.

Durante a pesquisa, foram coletados os seguintes documentos de pesquisa: a) uma autobiografia escrita no início do curso; b) filmagens de 19 aulas; c) notas de diários dos alunos; d) três entrevistas semi-estruturadas transcritas; e) notas de conversas informais com os participantes; f) notas de observação em sala de aula; g) uma representação visual das emoções; h) um questionário de apreciação sobre a participação na pesquisa. Além destes, foram utilizados roteiros fornecidos aos alunos, para orientá-los quanto às tarefas de pesquisa (ARAGÃO, 2007). Os enredos narrativos da pesquisa foram escritos conectando experiências passadas, presentes e projeçôes futuras, a partir dos diversos documentos de pesquisa. As representações visuais foram propostas como meio de expressão das emoçōes, pois emoções são difíceis de serem descritas em nossa cultura, tornando-se produtivas assim como seu uso em psicoterapias e em narrativas multimídia de aprendizagem de inglês (OATLEY; JENKINS, 1996; PAIVA, 2007a).

Os participantes foram entrevistados individualmente. Na primeira entrevista, foi explorada a autobiografia escrita, aprofundando questóes sobre história de vida, crenças e estilos de aprendizagem, eventos marcantes em sua trajetória, motivações e aspirações, expectativas e desafios frente ao curso e à pesquisa. Na segunda, foi discutida uma apresentação oral, rotinas de sala de aula em uma sessão de visionamento ${ }^{7}$ e as emoções predominantes em sala, suas origens e conseqüências. Na última, foram abordadas as representações visuais de suas emoções, conectando-as às suas histórias, além de uma apreciação final, quanto ao impacto da pesquisa em seu processo de aprendizagem. Na sala, o modo de participação foi observado. Neste artigo, as reflexões são pautadas, especialmente, por representaçôes visuais das emoçôes dos alunos sobre como se sentiam ao falar inglês e sobre sua trajetória na disciplina. Devido a limitações de espaço, as narrativas são utilizadas aqui de maneira condensada. As histórias detalhadas dos estudantes podem ser

7 Sessões de visionamento são discussões de experiências vividas em sala de aula estimuladas pela análise de determinadas cenas de aulas filmadas. (MICCOLI, 1997). 
acessadas em Aragão (2007). No que segue, passo a discutir o contundente papel das emoçóes nas práticas reflexivas dos estudantes.

\section{Emoções e práticas reflexivas}

Todos os participantes desta pesquisa indicaram que foi inusitado e significativo dar-se conta da maneira como suas histórias de aprendizagem influenciam suas condutas na sala de aula da disciplina Habilidades Integradas I. Nenhum deles havia feito nada parecido antes. Ao examinar as experiências de estudo, fora de sala de aula, de 86 alunos de Letras, através de um questionário, Cunha (2005) mostrou que a esmagadora maioria não tinha consciência de suas dificuldades como estudantes. Os estudantes envolvidos em sua pesquisa demonstravam pouco agenciamento em sua aprendizagem tanto em sala quanto fora dela. Minhas observações nesta pesquisa são similares às de Cunha (2005), Miccoli (1997, 2000, 2003) e Swain e Miccoli (1994). No questionário de apreciação, que foi distribuído ao final da pesquisa, realizei a mesma pergunta que Miccoli (1997, p. 271) havia feito a seus participantes: "Você já fez alguma atividade parecida antes?". A resposta negativa a esta pergunta por todos os participantes desta pesquisa reforça as observaçôes feitas por Miccoli (1997, p. 273) e por Cunha (2005).

Ao resgatar a última fala do participante desta pesquisa, Cheguevara, ao discutirmos o impacto da pesquisa em sua conduta, pode-se observar com ele que vivemos uma cultura que nega a reflexão e que se vê constantemente centrada na ação. Ele diz: "esta é uma cultura que falta reflexão cara", e como sugerem Maturana e Varela (2001, p. 30-31), ao refletirem sobre esta questão: "Essa situação de conhecer como se conhece é esquiva para a cultura ocidental, centrada na ação e não na reflexão, de modo que nossa vida é, geralmente, cega a si mesma”. Não seria exatamente isso a que se refere Cheguevara quando diz "a gente vai fazendo, vai fazendo e é difícil parar pra pensar"? Não seria a essa cultura cega a si mesma a que se referem os outros participantes desta pesquisa e os de Miccoli (1997) e Cunha (2005), ao dizerem que não haviam feito nada parecido anteriormente?

\footnotetext{
${ }^{8}$ Como apontado por Miccoli, em comunicação pessoal, esta seria umas das razões pelas quais os diários reflexivos funcionaram parcialmente nesta pesquisa. Os participantes não mantiveram uma reflexão sistemática com os diários por falta de uma cultura reflexiva consolidada em sala de aula.
} 
Neste contexto, o que dizer da crescente expansão das práticas reflexivas na formação dos professores no Brasil? Seria esta uma forte candidata a contribuir para uma mudança dessa cultura ao fomentar práticas reflexivas com professores em serviço e alunos de Letras em formação inicial? Certamente que sim, já que os professores são atores fundamentais nos tipos de dinâmicas de ensino e aprendizagem, e modelos de ação e convivência em sala de aula, criando ambientes nos quais somos socializados como alunos e, talvez, futuros professores. Além disso, ao participarem de práticas reflexivas, possivelmente esses professores possam desenvolver formas de refletir com os alunos sobre questôes presentes em seu cotidiano, criando maior sentido às suas açōes pedagógicas e à disciplina que ensinam. Porém, como bem nos alertam Dutra e Mello (2004), "a reflexão só ocorrerá se o participante realmente quiser se envolver no processo" (p. 50). Ao indicar essa disposição para a ação, essa emoção, as autoras argumentam que na reflexão os professores são ainda responsáveis pelas "ações que gerem mudanças em sua prática, caso elas ocorram" (p. 38), ou seja, dependendo das emoçôes envolvidas na reflexão, esta pode ser bloqueada, limitada, estimulada ou expandida. ${ }^{9}$

$\mathrm{Na}$ convivência com os participantes, buscava-se valorizá-los em sua legitimidade experiencial, sem emitir julgamentos. Considera-se aqui este tipo de convivência importante para se fomentar disposições emocionais e relações em sala de aula em que os alunos se permitam errar, refletir, se corrigirem e serem corrigidos, e, assim, talvez, aprender a partir de seus erros e reflexões. Arnold e Brown (1999, p. 8-13) argumentam que o professor é responsável por fomentar um clima de aceitação e valorização recíproca que estimule a autoconfiança dos alunos. Esse clima de sala aula busca reduzir componentes afetivos, tais como a ansiedade de exposição social, a inibição e a baixa autoestima, que bloqueiam a aprendizagem e o desenvolvimento das habilidades orais. Sobre isso, Mattos (2002, p. 132) discute como "as atitudes avaliativas de supervisores e pesquisadores pode causar sentimentos de inferioridade e medo no professor, prejudicando sua autoconfiança” e reclama por um ambiente propício para a formação de professores, baseado na constituição de uma relação de confiança com o pesquisador em face de uma situação livre de julgamentos. Mattos (2002) indica a reflexão como elemento favorável e fundamental para efetivar pequenas e significativas transformaçôes.

9 Stanley (1999) explora um conjunto de emoções inibidoras (medo, raiva, vergonha, culpa), assim como emoções catalisadoras (interesse, curiosidade, respeito pela perspectiva dos alunos) no processo reflexivo. 
O uso de uma interlocução que não realiza julgamentos estimula o respeito e a confiança necessária para que os alunos se arrisquem a usar a língua que estão aprendendo e reflitam sobre esse processo. Nesse espaço amplia-se a possibilidade de expandir açóes lingüísticas e reflexivas, livres do medo da avaliação negativa por uma audiência julgadora. Aqui, voltamos nossa observação para as ações, e não para aqueles que as realizam, por exemplo, ao adotar atividades de correção indireta para o tratamento dos erros, de forma com que um erro seja distinguido dentre os estudantes e não quem errou. Além disso, ao dar sentido à sua experiência na reflexão, os alunos-participantes sentem que sua experiência pode ser útil para outros estudantes, assim como foi útil para eles e que suas aflições, conflitos e desafios são comuns a outros colegas (Cf. MICCOLI, 1997; ARAGÃO, 2007; PAIVA, 2007a). Nesse processo, eles sentem que sua experiência é valorizada por si e por outros. Essas considerações vão ao encontro da dimensão afetiva que fortalece a auto-estima, ${ }^{10}$ comumente fragilizada na tarefa de aprender uma nova língua, que Arnold e Brown (1999) expōem a partir da psicologia humanista norte-americana. ${ }^{11}$

Booth e Pennebaker (2000), ao relatarem pesquisas conduzidas ao longo dos últimos vinte anos na área da saúde mental, argumentam que expressar experiências e sentimentos negativos, mesmo na escrita de um diário anônimo, apresenta vários benefícios para o bem estar corporal, psíquico e relacional das pessoas. Nesta pesquisa, os participantes, ao descreverem as emoções que sentiam restringir seu desempenho como falantes de inglês, e ao atribuírem sentido histórico a essas emoções, melhoraram suas relações consigo mesmos e com os outros que compunham o contexto de aprendizagem. Dar-se conta disso foi o primeiro passo em direção a transformações em suas condutas, caso estas sejam desejadas e mereçam o investimento devido, como nos alertam Miccoli (2007), Barcelos (2007), Dutra e Mello (2004) e Mattos (2002). Vale ressaltar que, como nos indica Miccoli (2007, p. 237), "você faz o pequeno e o grande acontece", ou seja, de pequenas perturbações geradas inicialmente na reflexão se fazem grandes transformações. Na reflexão passamos a considerar elementos que antes não eram observados conscientemente. A reflexão envolve ainda uma disposição para a dúvida e a incerteza. A certeza nega a reflexão, pois

\footnotetext{
${ }^{10}$ Arnold e Brown (1999) definem auto-estima como a avaliação que uma pessoa faz sobre seu próprio valor como indivíduo, um processo intimamente ligado à imagem que um constrói de si mesmo.

${ }^{11}$ Para sugestôes sobre dinâmicas de grupo, ver Arnold (1999).
} 
não questionamos o que se toma como certo. O medo também nos impede de refletir, pois não refletimos sobre aquilo que tememos ver, assim como não nos expressamos se tememos ser julgados negativamente. Emoções como vergonha, timidez e inibição - associadas ao medo de se expressar oralmente - são predominantes nas experiências dos participantes desta pesquisa, em especial, nas experiências de Arwen, Júlia e Sollylove.

\section{Emoções ao falar inglês: desafios e desejos}

Falar em inglês constituía um desafio para a maioria dos participantes desta pesquisa, assim como nas pesquisas de Miccoli (1997, 2000, 2001, 2003), Swain e Miccoli (1994) e Barcelos (2006). A partir da análise de inúmeras narrativas coletadas pelo projeto AMFALE, ${ }^{12}$ Paiva $(2005,2007 \mathrm{~b})$ nos mostra como é forte o desejo pelo desenvolvimento das habilidades orais por estudantes e também professores de línguas estrangeiras. Ao mesmo tempo em que esse desejo é latente, fica claro o desafio de se desenvolver tal habilidade no contexto das escolas brasileiras do ensino básico. Muitas dessas histórias de aprendizagem revelam a persistência, a luta, os conflitos e as frustrações daqueles que buscam realizar o enorme desejo de falar inglês. Os participantes desta pesquisa relataram a importância de estarem imersos num espaço que se sentissem seguros para falar inglês, no qual soubessem os nomes dos colegas e conhecessem um pouco de cada um deles. Este aspecto se confirma na percepção de que trabalhar com quem se conhece é mais produtivo (ARAGÃO, 2007; MICCOLI, 1997). Na pesquisa, observa-se que, para os participantes, os estranhos comumente os ameaçavam, limitando sua expressão oral, ao sentirem medo do que esses "estranhos" pudessem pensar deles. A expressão de sentimentos negativos pelos participantes se sobrepóe aos sentimentos positivos, assim como em Miccoli (1997, p. 138). Sentimentos de comparação e avaliação julgadora limitam o desempenho oral dos participantes.

Houve entre os participantes desta pesquisa uma constante comparação de seu próprio desempenho com o desempenho dos colegas ou com imagens idealizadas de falantes de inglês que nunca erram e não sofrem influência de

\footnotetext{
${ }^{12}$ AMFALE - Aprendendo com Memórias de Falantes e Aprendizes de Línguas Estrangeiras é um banco de dados que reúne narrativas de estudantes e professores de línguas e pesquisadores interessados em questôes de ensino e de aprendizagem de línguas, e é coordenado pela profa. Vera Lúcia Menezes de Oliveira e Paiva (http://www.veramenezes.com/amfale.htm).
} 
sua língua materna em sua expressão oral em inglês. Arwen, Sollylove e Júlia, especialmente, se viam condenadas pela ameaça de avaliação pelos colegas, pela professora, e por si próprios. Todas consideravam falar inglês pior do que de fato falavam, de acordo com observações de sala de aula. Esta percepção foi posta em cheque nas sessões de visionamento sobre suas apresentações orais e rotinas de sala de aula, assim como no estudo realizado por Miccoli (1997). No que segue, apresento as imagens comuns de Arwen, Sollylove e Júlia para representar as emoções predominantes ao falar inglês, assim como a indelével influência de suas histórias de aprendizagem em relação a essas emoçóes.
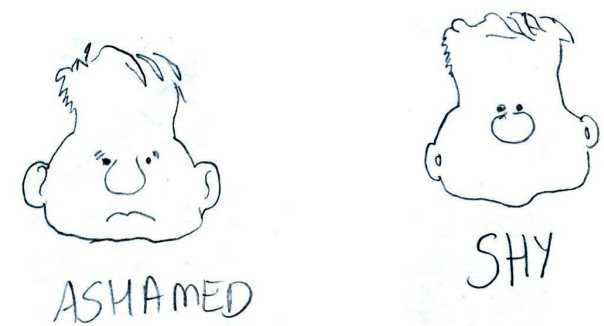

FlGURA 1 - Arwen e os sentimentos predominantes na sala de aula

Arwen se considerava uma pessoa tímida e temia falar em inglês na sala de aula. Dizia que sempre foi uma aluna tímida para se expressar em sala, especialmente no curso pré-vestibular. Nessa experiência mais recente, ao ser reprovada em sua primeira tentativa ao vestibular, Arwen decidiu se calar em sala, pois estava "faladora". Ao chegar à universidade, escutou de outros alunos que o inglês era a língua mais difícil da faculdade, por iniciar no nível intermediário, o que a levou a ter medo de não conseguir ser aprovada na primeira disciplina que cursava em inglês. Esse sentimento associado a sua "herança" ${ }^{13} \mathrm{da}$ escola e do cursinho, auxiliava na constituição de sua timidez. Arwen tinha medo do que os outros pensariam de si mesma a partir de sua expressão oral. Era a sua voz que expressava quem ela era como pessoa e estudante. Arwen se inibia ao acreditar que colegas, "as meninas que falam inglês bem", a estavam observando de uma maneira negativa e julgadora; situação semelhante à de Izabel, uma participante do estudo de Miccoli (1997). Notem que na imagem à direita, da primeira figura, com que indica sua timidez, falta uma boca. Ela pode expressar aqui a ausência de sua voz em

\footnotetext{
${ }^{13}$ Esta é exatamente a forma como Arwem se dirigia à continuidade de experiências que vivia na disciplina Habilidades Integradas I.
} 
sala de aula. De fato, Arwen quase não falava em sala, embora falasse muito fora dela! Sua timidez era situada na sala de aula de inglês.
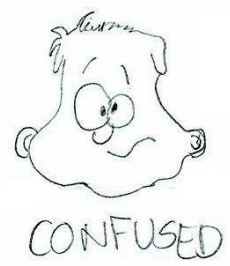
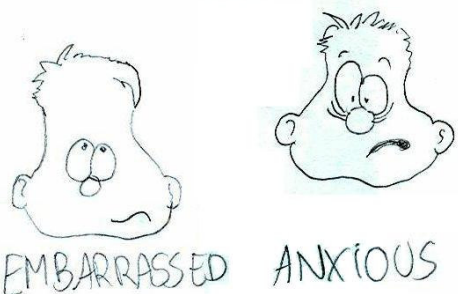

FIGURA 2 - Arwen ao falar inglês em sala: múltiplos sentimentos

Arwen sentia que soava falsa ao falar inglês, e se sentia como outra pessoa, um processo descrito por ela como confuso. Não conseguia falar o que queria numa voz que parecia não ser a dela. Sentia-se ansiosa e incapaz de expressar o que gostaria e isso a ameaçava (Cf. ARNOLD; BROWN, 1999). Além disso, a consciência sobre os tempos verbais e a dúvida sobre qual usar a confundia, na hora de se expressar em inglês. Arwen é a única participante que se refere ao sentimento negativo de se expressar publicamente em inglês usando o termo ansiedade. A experiência a que se refere Arwen é definida por Oxford (1999, p. 64) como ansiedade social comunicativa. Ela ocorre com a presença constante de uma preocupação sobre seu desempenho oral frente às outras pessoas e está relacionado com um tipo de auto-avaliaçáo negativa de seu próprio desempenho. Alunos que apresentam este quadro têm tendência a se retirar de interações sociais em sala de aula, mantendo-se em silêncio e respondendo com dificuldade, pavor e hesitação apenas quando chamados.

Assim como Arwen, Sollylove tinha medo de falar e ser criticada pelos colegas "que falam inglês bem". Desejava falar, mas como costumava dizer: "na hora não sai, trava!". Queria falar um inglês "perfeito" na sala de aula e tinha medo da avaliação negativa dos colegas frente à sua expressão oral, que considerava "imperfeita". Fora da sala de aula, era extrovertida, cantava cançōes em inglês em apresentações públicas, e foi a participante com quem mais conversei, mas na sala de aula se inibia. Ao cantar em inglês, buscava perfeição na pronúncia assim como ao falar na sala, já que a sala era o "espaço da técnica". Como Arwen e Júlia, a experiência de ter uma aula ministrada "somente em inglês" era nova, e ela ficou impressionada com a "pronúncia perfeita” da professora, o que contribuiu para a sua inibição. Embora tivessem sido poucas as experiências de aulas ministradas em inglês no ensino básico, Arwen, 
Sollylove e Júlia buscavam formas de desenvolver a língua inglesa fora da sala; comportamento também reportado nas pesquisas de Paiva $(2005,2006)$ e Barcelos (2006). Mas, quando cercada por pessoas que considerava falar melhor inglês que ela, sentia-se inibida. E, assim, embora tivesse desejo de falar, sentia a boca costurada e dificilmente se expressava em sala de aula.

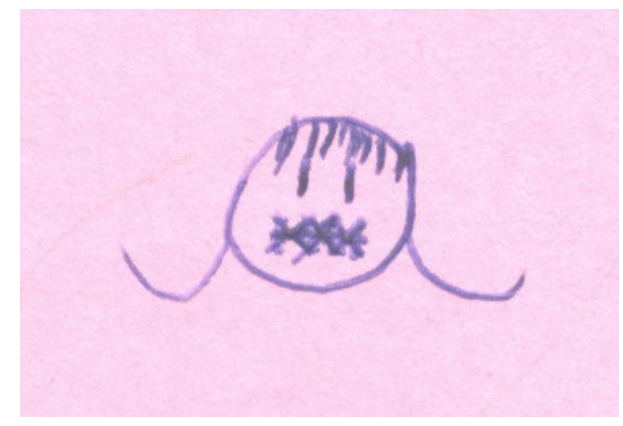

FIGURA 3 - Sollylove ao tentar falar inglês: travada com a boca costurada

Júlia vivia com intensidade o medo de crítica pelos colegas e pela professora, diferentemente das universitárias iniciantes Arwen e Sollylove, era repetente na disciplina em que a pesquisa foi conduzida. Ao descrever seu sentimento, ao falar inglês, como estivesse "pisando em ovos", indicava sua conduta cautelosa e desconfiada. Como Ana Esther, participante do estudo de Miccoli (1997), sentia-se condenada pela ameaça de ser criticada negativamente pelos colegas e sempre dizia: "será que o que estou falando é certo ou errado? O que eles vão pensar de mim?”. Júlia explicava que tinha medo de errar e ser motivo de zombaria pelos colegas da sala de aula, como havia sido por um colega na adolescência, um evento negativo marcante em sua história de aprendizagem de inglês.

De fato, este marco em sua trajetória sempre vinha à tona, ao apresentar cautela e desconfiança quanto ao que os outros iriam pensar de sua expressão oral em inglês. Fora da sala de aula, tinha que demonstrar o inglês que sabia para os amigos e em uma escola onde iniciara a trabalhar como professora de inglês, por isso justificava essa sensação como um assalto. Júlia ficava aterrorizada quando tinha que falar inglês nessas situaçôes. Ela caracterizava sua aprendizagem como uma empreitada difícil, dolorosa, de tal forma que "aprender a falar inglês passa a ser uma questão de luta, sobrevivência e sacrifício" (BARCELOS, 2006, p. 163). Júlia pisava em ovos na sala e se sentia assaltada fora dela tendo que apresentar o valor de seu conhecimento. 


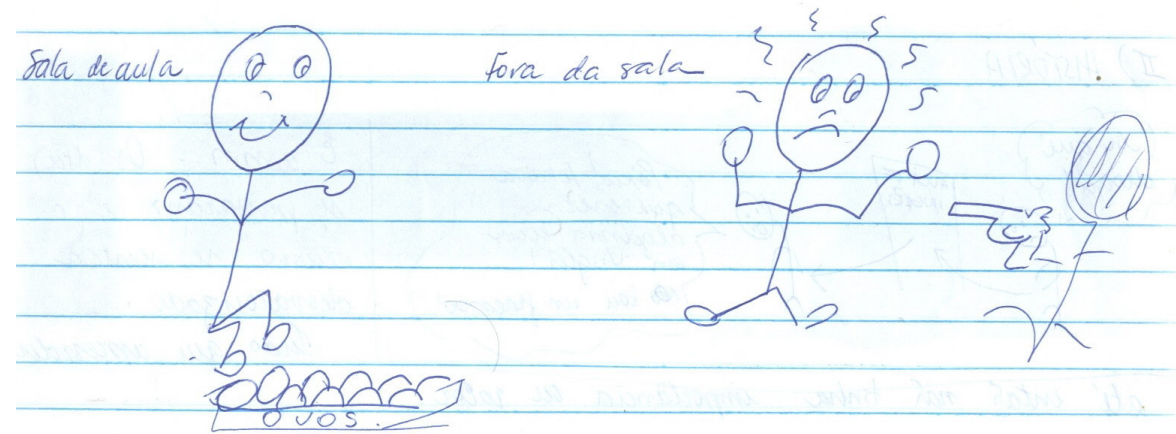

FIGURA 4 - Júlia falando inglês na sala de aula e fora dela

Por outro lado, todas as participantes trouxeram imagens positivas ao serem provocadas a imaginar como se sentiriam ao falar inglês com fluência, associando a imagem à sua história e ao evidente desejo de falar inglês com desenvoltura. Este era o maior sonho de todas elas: falar inglês com fluência. Como nos indica a primeira imagem a seguir, Sollylove se sentiria feliz, tranqüila, confortável e livre de suas preocupaçóes e da boca costurada, como ao ver um pôr do sol num lugar paradisíaco.

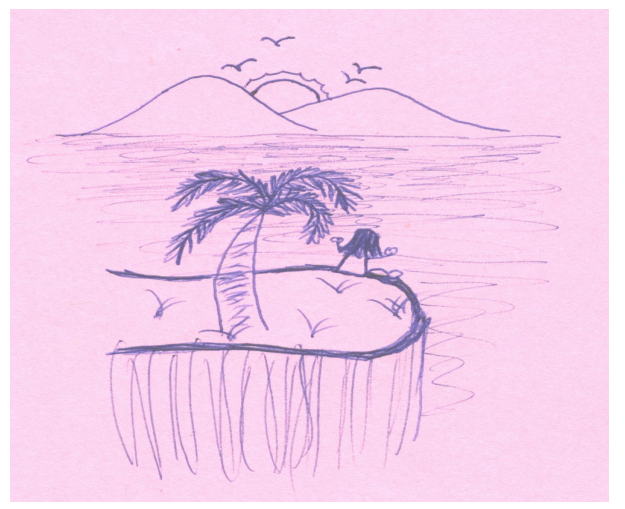

FIGURA 5 - Sollylove viverá tranqüila quando souber falar inglês

Já Arwen se sentiria feliz, satisfeita e confiante como numa festa, e assim como Sollylove estaria livre de seu estresse e de suas preocupaçóes, celebrando sua conquista. As imagens que agora traziam à reflexão representavam a esperança num caminho diferente, numa alternativa, num emocionar diferenciado. Era a visão de uma experiência futura atraente que, por sua vez, 
poderia desencadear um movimento de transformação positiva em direção da realização de seus desejos e interesses.
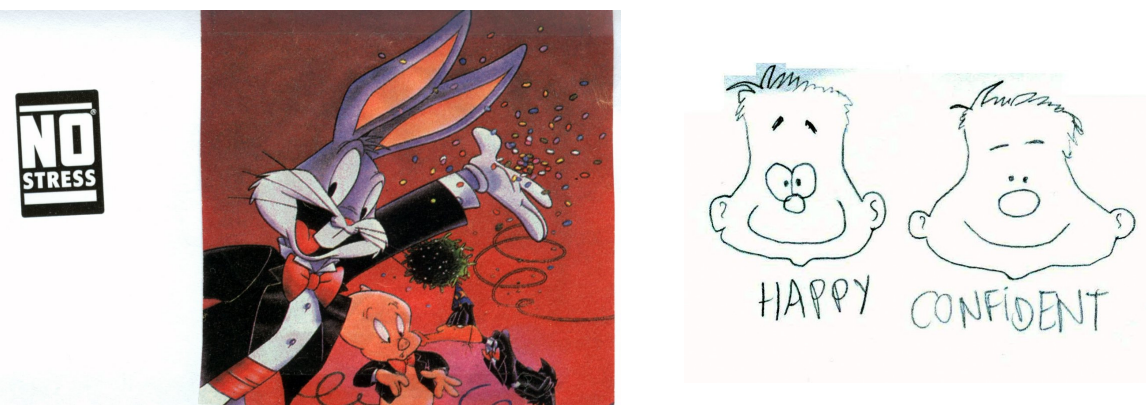

FIGURA 6 - Arwen e os sentimentos ao falar inglês com fluência

Júlia, que caracterizava sua aprendizagem como uma dolorosa luta, se sentiria "a dona do poder", ao vestir a capa e a coroa do rei após ter dominado o seu "bicho de sete cabeças", que era, como descrevia, a língua inglesa. Via sua aprendizagem, assim como sua própria vida, como uma batalha. Ao falar com fluência, estaria finalmente superior aos "súditos" que não dominam a língua inglesa e igual "às meninas que falam inglês".

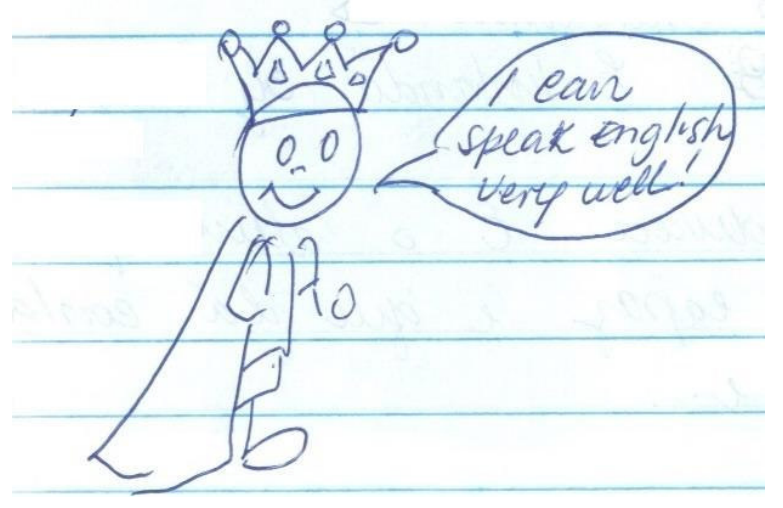

FIGURA 7 - Júlia falando inglês com fluência 


\section{Reflexão, emoção e pesquisa narrativa: experiências em transformação}

Nesta pesquisa, Arwen passou a observar sua timidez na sala de aula e como esse sentimento afetava seu desenvolvimento comunicativo e limitava a realização de seu desejo como falante de inglês. Arwen nunca havia parado para pensar sobre os diversos aspectos revelados em sua narrativa de aprendizagem. No questionário de apreciação da pesquisa, afirmou que, embora não tivesse conseguido "destruir seus pontos fracos", agora tinha consciência deles: "Caiu a ficha!". Mas faltava disposição para mudar: "Acho que não mudei muito, na prática. Passei a refletir mais sobre minha atitude em sala de aula, mas não fiz muito esforço para mudar”. Ao se ver filmada na sessão de visionamento, observou sua conduta tímida na sala de aula, e ao escutar sua apresentação oral percebeu que seu desempenho não era tão ruim quanto supunha.

Acredito que Arwen não queria abrir mão da certeza de que era uma aluna tímida. Como dizia: "sempre foi assim na escola" ou "era uma herança do cursinho". Descrevendo-se como tímida, conservava suas experiências prévias e dava continuidade à sua história e conduta como aluna tímida. Como podemos observar na representação de sua história na disciplina, ela inicia o semestre com sentimentos negativos e termina com sentimentos positivos; $\mathrm{o}$ que, somado a sua imagem de falante fluente, pode indicar um futuro diferente quanto ao desenvolvimento de suas habilidades orais e à superação de seus desafios. Notem que este movimento de sentimentos negativos para sentimentos positivos, proporcionado pela reflexão consciente sobre a prática, foi similar ao descrito na pesquisa de Swain e Miccoli (1994). Porém, note-se que a timidez é o sentimento que se vê presente continuamente em todas as etapas:

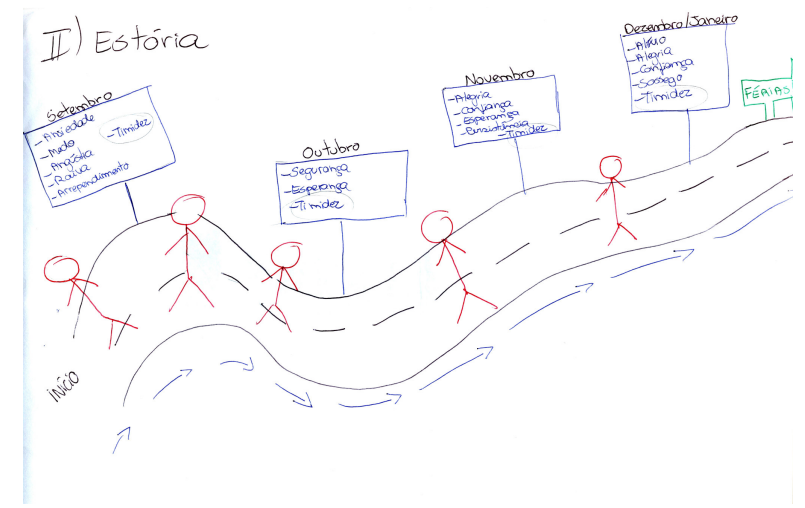

FIGURA 8 - Arwen e o semestre no curso Habilidades Integradas I: inglês 
Dizia a Arwen que poderia se arriscar mais para viver outras experiências com a língua. Isso era necessário para dispor de alternativas, de exemplos e sentimentos que lhe permitissem alterar tal comportamento que se conservava há tempos, como ela mesma narra em sua história. Pesquisas têm demonstrado que os alunos podem se beneficiar ao viver experiências diferentes que lhes permitissem experimentar sentimentos positivos com a língua (Cf. BARCELOS, 2007; MURPHEY, 2006). Assim como Arwen, Sollylove passou a observar suas dificuldades e voltou-se para o desenvolvimento de sua "prática de aprendizagem". Ao se ver filmada, observou que seu desempenho não era tão ruim quanto pensava. No questionário de apreciação sobre a pesquisa foi pedido que se comparasse do início ao final da pesquisa e ela respondeu: "Fiquei mais autônoma e mais envolvida no processo de aprender. Antes não me envolvia. Vi que a aprendizagem depende mais de mim do que do professor, e busquei métodos que atendessem às minhas necessidades. Creio que poderá ajudar-me futuramente ao me tornar professora”. E assim resume sua história:

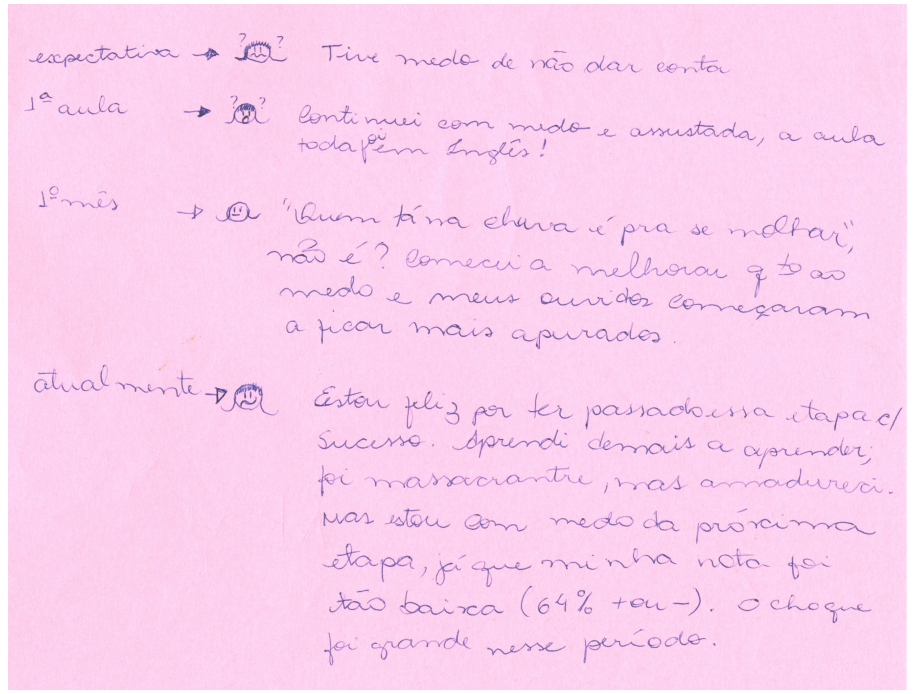

FIGURA 9 - Sollylove resume sua história na disciplina

Como Arwen e Sollylove, Júlia pôde refletir sobre sua aprendizagem, seus medos, desejos e desafios. Melhorou sua relação consigo mesma, com os colegas e, especialmente, com a professora da disciplina, na qual era repetente. Como Sollylove, Júlia passou a ter maior confiança em si mesma e a observar 
suas dificuldades. Identificou onde "estavam os ovos" e o modo adequado de pisá-los (fig. 4, neste artigo). Questionou algumas crenças, quanto à sua relação com a aprendizagem da língua que restringia seu desenvolvimento e conseguiu transformar sua prática de uma maneira mais contundente, se comparada às outras colegas. Júlia adotou outras posturas e ações efetivas em sala de aula, o que a auxiliou a transformar seu relacionamento no contexto de aprendizagem e a experimentar algo diferente com a língua, tendo experiências de sucesso e alterando sua imagem como estudante. Sua história na disciplina daquele semestre é também significativa em relação a essas mudanças. Observem, na representação visual de sua história, sua postura no final do semestre: sorrindo, ereta, "grande" e "confiante", diferentemente daquele croqui inicial, cabisbaixo e desanimado. A assimetria hierárquica entre Júlia e seu entorno relacional de aprendizagem havia se alterado, indicando uma transformação radical em sua posição inicial inferiorizada e "perdendo a batalha". No questionário de apreciação, afirmou que o principal efeito da pesquisa foi ter podido "mudar minha relação com a professora e assim melhorar minha aprendizagem".

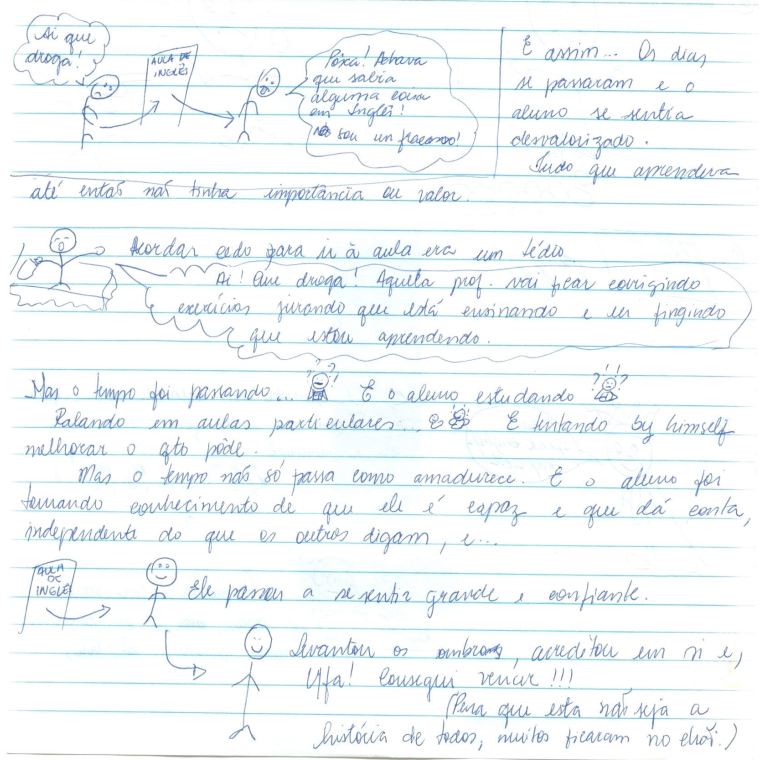

FIGURA 10 - Júlia, e uma história com final feliz 
Júlia conseguiu transformar sua conduta sob a influência de diversos elementos (Cf. ARAGÃO, 2005). De aluna calada, Júlia terminou a disciplina tomando longos turnos nas interaçóes orais proporcionadas em sala de aula. Semelhante situação foi identificada por Miccoli (1997) em duas participantes de sua pesquisa. Ao se dar conta de sua história e de seus desejos, elas decidiram investir em seu desejo pela mudança de sua conduta, e ao relacionarem-se diferentemente com outros colegas, passaram a ter novas experiências e interações que também as auxiliaram a configurar sua conduta de uma forma diferenciada. Arwen e Sollylove refletiram sobre seus sentimentos e os diversos aspectos contidos em sua história que modulavam sua conduta, mas não chegaram a superar as emoções que limitavam seu desempenho oral, na época da pesquisa. Durante o semestre, Arwen, Sollylove e Júlia passaram por fases emocionais semelhantes em sua aprendizagem. Iniciaram a disciplina com sentimentos de ansiedade, medo, vergonha, insegurança e a sensação de estarem perdidos. À medida que refletiram conscientemente sobre seus processos, deram sentido ao que viviam e queriam viver, e passaram por momentos de instabilidade, projetando diferentes trajetórias para o futuro e desenvolvendo segurança e responsabilidade por sua própria trajetória como estudante e pessoa, assim como em Swain e Miccoli (1994) e Miccoli (1997).

A produção de imagens que representam como se sentiriam na posição de falantes fluentes de inglês contribuiu para a transformação de suas experiências, ao terminarem sua história na disciplina como estudantes esperançosas, mesmo não tendo conseguido alcançar as mudanças desejadas naquele momento. As representaçôes dos sentimentos como falantes e de como poderiam se sentir ao progredir e se tornarem falantes fluentes pode promover diferentes identificações e metas. Nesse espaço, os alunos podem refletir sobre sua identidade atual e projetar identidades futuras, construindo distintas histórias que podem e desejam viver (TELLES, 2004; NORTON, 2000; MURPHEY, 2006). Por meio da projeção com imagens, podemos auxiliar os alunos a imaginar não só uma identidade distinta, mas as possíveis ações que contribuem para conquistá-la. Dessa forma, podemos auxiliá-los a transpor o espaço dos desejos e interesses para o espaço das açóes efetivas, ao dar uma forma e objetivo às suas esperanças e desejos de mudança e mostrar que, "desse ponto para uma ação transformadora, a distância é pouca. Para tal, é preciso usar procedimentos que viabilizem a reflexão sobre a prática" (MICCOLI, 2007, p. 236). 


\section{Considerações finais}

$\mathrm{Na}$ reflexão, damos significado às experiências e adentramos um domínio em que passamos a nos ver responsáveis pelos nossos atos, ao dar-nos conta das conseqüências de nossas emoções e ações em nosso entorno experiencial. Aqui tomamos para nós mesmos a responsabilidade do mundo em que vivemos com os outros e da conseqüência de nossas açóes para nós mesmos e para os que conosco convivem. Os alunos, ao se darem conta de suas experiências de aprendizagem, e do porquê delas, podem se perguntar: quero continuar assim? Quero seguir agindo de acordo com esta história que trouxe às mãos? Conheço as consequiências desta história e as desejo? Se não as desejo, estou disposto a construir outra história? Estando disposto, o que devo fazer para construir um caminho alternativo que seja apropriado aos meus interesses e desejos?

Quando refletimos, vivemos uma transformação em nossa conduta e podemos observar e agir de uma forma que antes não podíamos. Na reflexão não se volta ao mesmo ponto de partida, mas se desloca num fluir contínuo transformando a experiência anterior e aí surge uma nova temporalidade, uma nova compreensão pessoal e dimensão relacional e situacional. Como seres humanos, nossa experiência é uma história de transformações contínuas na reflexão e na ação e é por isso que surgem novos domínios de fenômenos no seu devir. Seres vivos e suas circunstâncias mudam em conjunto, como é evidente na representação das experiências dos estudantes desta pesquisa ao longo do semestre. É nesse processo que a reflexão desempenha um papel central e fundamental. No olhar reflexivo, ao observar nossa própria experiência, podemos agir de acordo com nossas preferências, desejos, ideologias e interesses de forma consciente e responsável. Porém, as ações que surgem como conseqüência da autoconsciência do que se vive ou se viveu depende do espaço emocional no qual uma pessoa adentra depois do surgimento dessa autoconsciência. Sua ação não fica condicionada à emoção presente na reflexão, mas pode passar a outro domínio sobre o qual um conjunto de outros elementos pode entrar em jogo na dinâmica.

\section{Ainda algumas palavras}

Ao promover visões futuras distintas das atuais, neste caso, como falantes fluentes de inglês, os alunos se distinguem da situação presente, assim como da continuidade de suas experiências passadas, e se tornam conscientes de como gostariam de ser. Projetam sonhos e desejos. Porém, há de se comprometer efetivamente com esses desejos e lutar por eles na prática. Como seres vivos, 
vivemos um constante presente, mas na linguagem somos capazes de refletir sobre nosso passado e assim dar coerência ao nosso presente e imaginar um futuro que pode ser diferente de nosso passado e presente. Na reflexão sobre as histórias de aprendizagem foi esse o processo vivido pelos participantes. É na reflexão sobre nossa experiência que tomamos consciência do mundo em que vivemos e no qual queremos viver. A partir daí podemos aceitar, rejeitar e modificar esse mundo. Aqui transformamos inevitavelmente as descriçôes de nós mesmos e nossas circunstâncias, e aí vivemos uma nova experiência, um novo olhar e um novo mundo.

Antes de encerrar essas reflexões, gostaria de oferecer algumas idéias aos professores de línguas a partir das experiências relatadas aqui. Creio que podemos enriquecer nossa atividade ao:

- orientar o emocionar do aluno para uma expansão reflexiva, valorizando sua experiência, seus interesses, suas dúvidas e questionamentos;

- fomentar atividades em que aprendam os nomes uns dos outros e troquem pequenas informaçóes pessoais, trabalhando relaçôes inter-pessoais;

- escrever autobiografias, que podem ser lidas por um colega que elaborará um questionário para entrevistar o escritor oralmente ou por cartas;

- discutir sua própria narrativa de aprendizagem com os alunos e aproveitar a oportunidade para conhecer um pouco da história deles;

- promover debates sobre as histórias, crenças, estilos e estratégias de aprendizagem levantadas nas narrativas orais, escritas ou imagéticas;

- criar formas em que os alunos percebam sua voz na língua, utilizando-se, por exemplo, de gravadores de áudio, vídeo e tocadores de MP3;

- realizar atividades de representação visual das emoções e experiências, podendo-se elaborar um cartaz com imagens que representem o que desejam atingir e propor planos de açóes para alcançar seus desejos;

- propor formas de enfrentamento da inibição, mesmo com apresentações orais, por exemplo, se inicialmente são desconfortáveis, podem aos poucos mudar seus efeitos, acostumando-se com a fisiologia e as sensações psíquicas desencadeadas por essa atividade de exposição oral;

- esclarecer os procedimentos pedagógicos da disciplina, discutir atitudes de convivência esperadas, encorajar disposições positivas;

- incentivar pequenos esforços e experiências de sucesso e estimulá-los a superar seus desafios, valorizando pequenas transformações. 
ABSTRACT: This article explores the influence of a narrative research on the language learning experiences of undergraduate students of English. As they reflect upon their language learning histories, they give voice and meaning to their experiences and their self-esteem improves. Their language learning histories reveal the relevance of emotions in their oral skills development, reflection, and responsibility for their professional trajectories. Three participants transformed their language experiences by reflecting on the emotions that restrained their speaking skills and projecting images that would represent their desire to become fluent speakers. However, transforming their desires into actions entails dealing with investments that may go beyond reflection fostered by this research.

KEY-WORDS: narrative research; emotions; language learning experiences; English

\section{Referências Bibliográficas}

ABRAHÃO, M. H. V. (Org.). Prática de ensino de língua estrangeira: experiências e reflexôes. Campinas: Pontes, 2004.

ARAGÃO, R. Cognição, emoção e reflexão na sala de aula: por uma abordagem sistêmica do ensino/aprendizagem de inglês. Revista Brasileira de Lingüistica Aplicada, v. 5, n. 2, p. 101-122, 2005.

ARAGÃO, R. C. São as histórias que nos dizem mais: emoção, reflexão e ação na sala de aula. 2007. Tese (Doutorado em Estudos Lingüísticos) - Faculdade de Letras, Universidade Federal de Minas Gerais, Belo Horizonte, 2007.

ARNOLD, J. Affect in language learning. Cambridge: Cambridge University Press, 1999.

ARNOLD, J.; BROWN, H. D. A map of the terrain. In: ARNOLD, J. (Ed.). Affect in language learning. Cambridge: Cambridge University Press, 1999.

BARCELOS, A. M. F. Narrativas, crenças e experiências de aprender inglês. Linguagem \& Ensino. v. 9, p. 145-175, 2006.

BARCELOS, A. M. F. Reflexôes acerca da mudança de crenças sobre ensino e aprendizagem de línguas. Revista Brasileira de Lingüistica Aplicada, v. 7, n. 2, p. 109-138, 2007.

BENSON, P.; NUNAN, D. Learners'stories: difference and diversity in language learning. Cambridge: Cambridge Universtiy Press, 2004.

BOOTH, R. J.; PENNEBAKER, J. W. Emotions and immunity. In: LEWIS, M.; HAVILAND-JONES, J. M. (Ed.). Handbook of Emotions. New York: The Guilford Press, 2000. p.558-572.

CELANI, M. A. A. Professores e formadores em mudança - relato de um processo de reflexão e transformação da prática docente. Mercado de Letras: Campinas, 2003. 
CLANDININ, J.; CONNELLY, M. Narrative Inquiry: experience and story in qualitative research. San Francisco: Jossey Bass Publishers, 2000.

CUNHA, N. B. Experiências de aprendizagem: um estudo de caso sobre as experiências fora da sala de aula de alunos de Letras-Inglês em uma instituição particular de ensino superior. 2005. Dissertação (Mestrado em Estudos Lingüísticos) Faculdade de Letras, Universidade Federal de Minas Gerais, Belo Horizonte, 2005.

DUTRA, D. P. A metalinguagem e o sistema pedagógico do professor In: DUTRA, D. P.; MELLO, H. (Org.) A gramática e o vocabulário no ensino de inglês: novas perspectivas. Belo Horizonte: Faculdade de Letras da UFMG, POSLIN, 2004. p. 17-40.

DUTRA, D. P.; MELLO, H. A prática reflexiva na formação inicial e continuada de professores de língua inglesa. In: ABRAHÃO, M. H. V. (Org.). Prática de ensino de língua estrangeira: experiências e reflexões. Campinas: Pontes Editores, 2004. p. 31-43.

LEFFA, V. O professor de linguas estrangeiras - construindo a profissão. Pelotas: Educat, 2001.

JOHNSON, K.; GOLOMBEK, P. Teacher's narrative inquiry as professional development. New York: Cambridge University Press, 2002.

MATTOS, A. M. A. O professor no espelho: conscientização e mudança pela auto-observação. Revista Brasileira de Lingüística Aplicada, v. 2, n.1, p. 121-156, 2002.

MATURANA, H.; VARELA, F. A árvore do conhecimento. São Paulo: Palas Athena, 2001.

MATURANA, H. Uma abordagem da educação atual na perspectiva da biologia do conhecimento. In: MATURANA, H. (Org.). Emoções e linguagem na educação e na política. Belo Horizonte: Ed. UFMG, 1998. p.11-35.

MATURANA, H.; BLOCK, S. Biologia del emocionar y alba emoting. Santiago del Chile: Dolmen Ediciones, 1996.

MICCOLI, L. S. Learning English as a foreign language in Brazil: a joint investigation of learners' experiences in a university classroom. 1997. Tese (Doutorado em Educação) - Ontario Institute for Studies in Education, Universtiy of Toronto, Toronto, 1997.

MICCOLI, L. S. A deeper view of EFL learning: students' collective classroom experiences. Claritas, v. 6, n. 3-4, p. 185-204, 2000.

MICCOLI, L. S. Individual classroom experiences: a socio-cultural comparison for understanding EFL classroom learning. Ilha do Desterro, n. 41, v. 1, p. 61-91, 2003. 
MICCOLI, L. S. A experiência na lingüística aplicada ao ensino de línguas estrangeiras: levantamento, conceituação, referências e implicações para pesquisa. Revista Brasileira de Lingüistica Aplicada, v. 6, n. 2, p. 207-248, 2007.

MURPHEY, T. Language hungry! An introduction to language learning fun and self-esteem. Brighton: Helbiling Languages, 2006.

NORTON, B. Identity and language learning: gender, ethnicity and educational change. London: Longman, 2000.

OATLEY, K.; JENKINS, J. Understanding emotions. Oxford: Blackwell Publishing, 1996.

OXFORD, R. L.; GREEN, J. Language learning histories: learners and teachers helping each other understand learning styles and strategies. TESOL Journal, v. 5, p. 20-23, 1996.

OXFORD, R. L. Anxiety and the language learner: new insights. In: ARNOLD, J. (Ed.). Affect in language learning. Cambridge: Cambridge University Press, 1999. PAIVA, V. M. O. A LDB e a legislação vigente sobre o ensino e a formação de professor de língua inglesa. In: TEIXEIRA, C. M.; CUNHA, M. J. C. (Org.). Caminhos e colheitas: ensino e pesquisa na área de inglês no Brasil. Brasília: Editora da UNB, 2003. p. 53-84.

PAIVA, V. L. M. O. Memórias de aprendizagem de professores de língua inglesa. Contexturas, São Paulo, v. 9, p. 63-78, 2006.

PAIVA, V. L. M. O. Autonomia e complexidade: uma análise de narrativas de aprendizagem. In: FREIRE, M. M.; ABRAHÃO, M. H. V.; BARCELOS, A. M. F. (Org.). Lingüistica aplicada e contemporaneidade. Campinas: Pontes, 2005.

PAIVA, V. L. M. O. Letramento digital através de narrativas de aprendizagem de língua inglesa. Crop, v. 12, p. 1-20, 2007a.

PAIVA, V. L. M. O. As habilidades orais nas narrativas de aprendizagem. Trabalhos em Lingüistica Aplicada. v. 46, n.2, p.165-179, 2007b.

PAVLENKO, A. Emotions and multilingualism. Cambridge: Cambridge University Press, 2005.

SCHUMANN, J. The neurobiology of affect in language. Boston: Blackwell, 1997.

STANLEY, C. Learning to think, feel and teach reflectively. In: ARNOLD, J. (Ed.). Affect in language learning. Cambridge: Cambridge University Press, 1999. p. 109-124.

SWAIN, M.; MICCOLI, L. Learning in a content-based, collaborativelystructured course: the experience of an adult ESL learner. TESL Canada Journal, v. 12, n. 1, p. 15-28, 1994. 
TELLES, J. “É pesquisa, é? Ah, não quero não bem!" Sobre pesquisa acadêmica e sua relação com a prática do professor de línguas. Linguagem \& Ensino, v. 5, n. 2, p. 91-116, 2002.

TELLES, J. Reflexão e identidade profissional do professor de LE: que histórias contam os futuros professores?. Revista Brasileira de Lingüistica Aplicada, v. 4, n. 2, p. 57-83, 2004.

Recebido em março 2008. Aprovado em maio 2008. 